$$
\begin{gathered}
\text { 중국 산동성 연태시 고등학생들의 체중조절 경험과 } \\
\text { 체형인식 및 섭식장애 실태 } \\
\text { 우 문 정·류호 경 } \\
\text { 부산대학교 식품영양학과 }
\end{gathered}
$$

\title{
The Study of the Weight Control Experiences, Body Image Perception and Eating Disorder Status of High School Students in Yantai City, Shandong Province, China Yu, Wen Jing · Ryu, Ho Kyung ${ }^{\dagger}$
}

Dept. of Food Science and Nutrition, Pusan National University, Pusan, Korea

\begin{abstract}
This study was conducted to find out the weight control experiences, body image perception and eating disorder status of high school students in Yantai City, Shandong Province, China. The subjects of the study were 457 high school students in Yantai City. The results were as follows. The ratio of underweight and overweight and obesity of the subjects were $20.0 \%$ and $12.6 \%$ respectively. And $35 \%$ of the subjects had weight control experiences. There were significant differences according to the students' gender, location and BMI. In body image perception, the subjects who were normal and underweight overestimated their body figure, and the subjects who were overweight and obese underestimated their body figure. The girls wanted to have extremely skinny figure than standard figure and the degree of dissatisfactions with their figure was high. In the case of overweight and obese students, it showed a high degree of dissatisfaction of their body image. The ratio of the eating disorder group and eating disorder risk group were $7 \%$ and $19.3 \%$, Compared to the students in rural areas, downtown students had significantly higher ratio of eating disorder. In conclusion, the education of healthy body weight and body image is necessary to the students in Yantai City, China. Especially the female students who live in downtown are considered to be the most important subjects of nutrition education.
\end{abstract}

Key words: weight control, body image, EAT-26, high school students, Yantai

This work was supported by a 2-Year Research Grant of Pusan National University 접수일: 2013년 6월 5일 심사일: 2013년 12월 13일 게재확정일: 2013년 12월 17일

Corresponding Author: Ryu, Ho Kyung Tel: 82-51-510-7397 Fax: 82-51-583-3648 e-mail: hokryu@pusan.ac.kr

This is an Open-Access article distributed under the terms of the Creative Commons Attribution Non-Commercial License (http://creativecommons.org/licenses/by-nc/3.0) which permits unrestricted non-commercial use, distribution, and reproduction in any medium, provided the original work is properly cited. 


\section{I. 서론}

중국은 1959년, 1982년 및 1992년 등 3차에 걸 쳐 전국적인 영양조사를 실시하였고 $(\mathrm{Ge}$ et al. 1995), 2002년에 실시한 “중국 국민 영양과 건강 조사"는 영양조사와 더불어 만성질환 조사를 함 께 시행하였다(Yang et al. 2010). 중국의 국민영 양건강조사 결과 1982 년에는 과체중이 $6 \%$ 로 나 타났고(Ministry of Health, PRC 2004), 1992년에는 과체중 $16.4 \%$, 비만이 $3.6 \%$ 로 나타났다 $(\mathrm{Ge}$ et al. 1995). 그리고 가장 최근 자료인 2002년 조사에 서는 과체중이 $22.8 \%$, 비만이 $7.1 \%$ 로 나타났다 (Yang et al. 2010). 이는 중국에서 과체중과 비만 의 비율이 급격히 증가하고 있음을 보여주는 자 료이다. 성인들의 비만율이 증가하는 것과 마찬 가지로 중국 청소년의 비만율도 빠르게 증가하고 있다. 최근 중국 청소년의 비만은 $8.1 \%$ 로 나타났 고, 특히 대도시 청소년의 과체중은 $20 \%$ 로 나타 났다(Yang et al. 2010).

비만은 청소년의 생리적 건강에 매우 위험한 요소이다. 청소년기에 비만이나 과체중이 되면 호르몬 분비의 이상을 초래할 수 있고 당뇨를 유 발하기도 한다. 혈액순환도 영향을 받아 고혈압 의 발생도 빈번히 나타난다. 더구나 청소년기는 아동에서 성인으로 이행되는 시기로 신체적 성장 과 더불어 성적 성숙도 활발하게 이루어지는데 비만과 과체중은 성기관의 발육에도 큰 영향을 미칠 수 있다. 따라서 과체중이나 비만인 경우 체중조절을 통해 적절한 체중으로 변화시키고, 정상체중을 유지하는 것이 필요하다. 그러나 체 중조절행동에는 적절한 규칙적인 운동과 식사량 의 조절 등 건강한 체중조절행동 뿐 아니라 지나 친 단식, 원 푸드 다이어트, 의사의 처방 없이 살 빼는 약을 먹는 등 부적절한 체중조절행동도 있 다. 건강한 체중조절행동은 청소년에게 신체적, 정신적 도움을 줄 수 있으나 부적절한 체중조절 행동은 청소년기 뿐 아니라 이 후의 건강에까지 영향을 줄 수 있어 청소년기의 올바른 체중조절 행동은 매우 중요하다(Lobstein et al. 2004).

청소년기의 체중조절행동과 관련하여 성, 연령, 사회경제적 상태, 부모의 교육수준, 실제의 비만
도, 주관적 체형인식, 신체 만족도, 자아존중감 등이 영향을 미치는 요인으로 연구되어 왔다(Ryu 1997; Ryu \& Yoon 1998; Kwon et al. 2002; Her et al. 2003; Lee \& Yun 2003; Kim \& Shin 2008; Soh et al. 2008; Ryu \& Contento 2011). 또한 체형에 대한 사회적 수용정도는 사람들의 비만에 대한 인식 형성에 영향을 주어 사회의 비만 인구비율 의 변화를 초래할 수 있는 요소로 작용되어 왔다 (Must et al. 1999). 오늘날의 청소년들은 매우 마 른 체형을 선호하고 있는데 그러한 경향을 보여 주는 한 예로 미국에서 지난 30년 동안 여성잡지 에 나온 여성의 체형은 갈수록 날씬한 모습으로 변화되어왔다는 것이다(Psujek et al. 2004). 그런 데 많은 사람들이 희망하는 이상적인 체위를 갖 고 싶어 하는 것은 청소년들에게서 지나친 체중 조절이나 좋지 않은 섭식태도를 갖게 하는 원인 이 될 수 있고, 이는 청소년들의 생리적, 심리적 건강에 큰 영향을 미친다고 한다(Ingledew \& Sullivan 2002). 선행연구에 의하면 식사장애는 주 로 10 대 후반부터 20대에 걸쳐 나타나며(Treasure et al. 2010), 이에 따라 청소년기의 섭식장애 위 험도에 영향을 미치는 연구와 이를 줄일 수 있는 방안에 관심이 모아지고 있다(Currin et al. 2005). 이러한 경향은 미국 및 유럽지역 뿐 아니라 일 본, 싱가폴, 중국 등 아시아지역 청소년에서도 증 가하고 있으며(Huon et al. 2002; Yamatsuji et al. 2003; Ho et al 2006; Chen \& Jackson 2008; Liang et al. 2008), 특히 청소년들이 선호하는 여성의 체형은 남자보다 더 날씬한 체형이라고 한다 (Cash et al. 2005).

1997년에 국제비만위원회에서 전문가들은 성 인처럼 아동과 청소년들에서도 $\mathrm{BMI}$ 로 체지방지 수와 비만 발생율을 반영하였다(Bellizzi \& Dietz 1999). 그러나 중국에서는 비만 발생율이 매우 높아지고 있음에도 비만 판정을 위한 통일된 검 사 표준이 없었다. 이에 따라 국제생명과학학회 중국 비만문제팀은 BMI 지수와 허리사이즈를 중 심으로 비만 진단 기준을 만들고(Zhou 2002), 2003년 11월에 중국 아동과 청소년의 과체중과 비만의 BMI지수 기준을 발표했다(Chengye 2004)

중국은 매우 큰 나라이고, 지역에 따라 식생활 
양식과 태도 및 비만에 대한 인식 등이 매우 다 르므로 중국 전체의 평균만으로 각 지역의 상황 을 설명하기엔 부족한 부분이 많다. 따라서 각 지역의 식생활 실태나 영양의 문제를 구체적으로 파악하는 것이 그 지역의 주민들을 위한 영양정 책에 매우 필요할 것으로 생각된다. 이에 본 연 구는 중국 산동성 연태 지역에 있는 고등학생들 을 대상으로 체위 실태를 조사하고, 체중조절경 험과 체형에 대한 인식, 그리고 섭식장애증상 등 의 실태가 어떠한지를 알아보기 위해 실시되었 다. 또한 이러한 실태가 남녀의 성별에 따라, 그 리고 동일한 연태시에 소재하고 있더라도 도심지 역과 농촌지역의 학생들에서 어떠한 차이가 있는 지를 살펴보고자 하였다.

\section{II. 연구방법}

\section{1. 조사 대상 및 방법}

본 연구는 2012년 3월에 중국 산동성 연태시 에 있는 고등학교의 학생들을 대상으로 실시하였 다. 연태시의 도심에 있는 연태제 1 고등학교, 연태 제3고등학교, 연태제4고등학교 등 3 개교와 연태 시에 속해 있으나 농촌 지역에 있는 연태래주제 1 고등학교, 연태서하제 1 고등학교, 연태초원제 2 고 등학교 등 3 개교 총 6 개교에서 설문지를 이용하 여 조사를 실시하였다. 조사 참여자는 연구의 목 적과 참여자의 권리에 관한 설명을 들은 후, 이 에 동의한 사람만 응답하도록 하였다. 전체 조사 참여자는 500명이었으나 회수된 설문지는 461 부 였으며, 이중 주요항목에 대한 응답이 없는 설문 지를 제외한 457 부를 최종 분석에 사용하였다.

\section{2. 조사 내용}

설문지는 선행 연구(Ryu 1997; Yang et al. 2010; Ryu \& Contento 2011)를 참고하여 문항을 개발 한 후 중국고등학생의 특성을 고려하고, 전문가 들의 의견을 수용하여 설문지를 개발하였다. 그 후 예비조사를 통하여 설문의 내용을 수정 보완 하여 최종 설문지를 확정하였다. 설문내용은 조 사 대상자의 일반적인 상황(5문항), 체중조절 경
험과 방법에 관한 질문(7문항), 체형인식(3문항), 섭식장애(EAT-26, 26문항)에 대한 항목 등으로 구성되었다.

체형인식에 관한 질문은 Stunkard et al.(1980) 의 그림을 참고하여 개발한 체형그림(Ryu 1997) 을 제시한 후 현재의 본인의 체형, 본인이 원하 는 체형, 이상적이라고 생각하는 체형 등을 그림 에서 선택하게 하였다. 가장 마른체형인 $\mathrm{A}$ 로부터 가장 뚱뚱한 체형인 I까지에 각각 1점부터 9점까 지의 값을 부여하여 점수로 환산하였다. 그리고 현재의 체형의 값과 본인이 원하는 체형의 값의 차이를 체형에 대한 불만족도로 나타내었다.

섭식장애 실태는 EAT-26(Garner et al. 1982)을 이용하였다. 섭식태도에 관련된 26개 문항에 '전 혀 아니다'로부터 '항상 그렇다'까지 6점 척도 중 자신의 생각이나 느낌에 적합한 곳에 응답하게 하였고, 이 중 '전혀 아니다' '거의 아니다' '때때 로 그렇다’는 0점, 섭식장애의 경향이 있는 쪽의 '자주 그렇다'는 1점, '매우 자주 그렇다'는 2점, ‘항상 그렇다'는 3점으로 하여 점수를 산정한 후 그 합계가 20점 이상은 '섭식장애군', 10 점에서 19점은 '위험군', 9점 이하는 정상군으로 설정하 였다.

대상자의 특성에 따른 차이를 알아보기 위하 여 성별과 연태시의 도심지역과 농촌지역을 구분 한 지역별 차이를 비교분석하였다. 또한 BMI가 체중조절의 경험과 체형인식, 섭식장애태도에 영 향을 미칠 것으로 생각되어 이에 따른 차이도 비 교분석하였다.

또한 체형군의 분류는 2003년 11월에 만들어 진 중국 아동과 청소년의 비만 진단기준(Chengye 2004) 중 15 세의 BMI 기준을 이용하여 실시하였 다. 이 기준에 의해 $18.5 \mathrm{~kg} / \mathrm{m}^{2}$ 미만은 저체중, $18.5 \mathrm{~kg} / \mathrm{m}^{2}$ 이상 $23.5 \mathrm{~kg} / \mathrm{m}^{2}$ 미만은 정상체중, $23.5 \mathrm{~kg} / \mathrm{m}^{2}$ 이상 $26.8 \mathrm{~kg} / \mathrm{m}^{2}$ 미만은 과체중, $26.8 \mathrm{~kg} / \mathrm{m}^{2}$ 이상은 비만 으로 분류하였다.

\section{3. 자료 처리 및 분석}

본 연구의 모든 자료는 SPSS 18.0 을 이용하여 분석하였다. 각 그룹에 대해 기술통계분석으로 빈 도, 평균 및 표준편차를 산출하였고, 그룹간의 유 
의성을 검증하기 위하여 교차분석을 실시하였다.

\section{III. 결과 및 고찰}

\section{1. 조사대상자의 일반적인 특성}

조사대상자의 일반적인 특성은 Table 1 과 같 다. 조사대상자의 나이는 평균이 15.6세였고, 남 학생이 208명(45.5\%), 여학생이 249명(54.5\%)으로 구성되었다. 지역적으로는 도심지역의 학생이 208 명(45.5\%), 농촌지역의 학생이 249명(54.5\%)이 었다.

\section{2. 조사대상자의 체위 실태}

조사대상자의 체위는 설문지에 본인이 직접 기록한 수치를 이용하였다. 남학생은 평균 신장
$177.6 \mathrm{~cm}$ 에 체중 $67.8 \mathrm{~kg}$ 이었고, $\mathrm{BMI}$ 의 평균은 21.5 이었다, 여학생은 평균 신장 $165.1 \mathrm{~cm}$, 체중 $55.1 \mathrm{~kg}$ 으로 BMI의 평균은 20.3이었다(Table 2). 이는 동 일한 연령층의 학생을 대상으로 한 한국 학생의 평균치(Kim \& Shin 2008; Yim 2010)와 비교할 때 남 - 녀 학생 모두 신장과 체중은 중국 학생들이 더 크고, BMI는 유사한 것으로 나타났다. 한국과 중국 일부 지역 대학생을 대상으로 조사한 연구 (Lee \& Sun 2013)에서도 중국 학생들이 한국 학 생들보다 신장이 큰 것으로 조사되었다.

체질량지수(BMI)를 기준으로 체형군을 분류한 결과는 Table 3 과 같다. 조사대상자는 저체중 비 율이 $20.0 \%$, 과체중과 비만은 각각 $8.6 \%$ 와 $4.0 \%$ 로 저체중의 비율이 높음을 알 수 있었다. 이는 남녀 학생 간에 유의적인 차이가 있었는데 남학

Table 1. General characteristics of subjects

\begin{tabular}{lccccc}
\hline \multicolumn{1}{c}{ Region } & School & Age & Male & Female & Total \\
\hline \multirow{3}{*}{ Downtown area } & A & $15.6 \pm 0.5^{1)}$ & $32(45.7)^{2)}$ & $38(54.3)$ & $70(100.0)$ \\
& B & $15.5 \pm 0.5$ & $37(51.4)$ & $35(48.6)$ & $72(100.0)$ \\
& C & $15.6 \pm 0.5$ & $33(50.0)$ & $33(50.0)$ & $66(100.0)$ \\
\multirow{2}{*}{ Rural area } & D & $15.6 \pm 0.6$ & $40(47.6)$ & $44(52.4)$ & $84(100.0)$ \\
& E & $15.6 \pm 0.6$ & $31(38.8)$ & $49(61.2)$ & $80(100.0)$ \\
Total & F & $15.5 \pm 0.6$ & $35(41.2)$ & $50(58.8)$ & $85(100.0)$ \\
\hline
\end{tabular}

1) Mean \pm SD

2) $\mathrm{N}(\%)$

Table 2. Physical status of the subjects

\begin{tabular}{lcrc}
\hline & \multicolumn{2}{c}{ Gender } & \multirow{2}{*}{ t-value } \\
\cline { 2 - 4 } & \multicolumn{1}{c}{ Male } & Female & $23.534^{*}$ \\
Height $(\mathrm{cm})$ & $177.6 \pm 6.0^{1)}$ & $165.1 \pm 5.0$ & $11.236^{*}$ \\
Weight $(\mathrm{kg})$ & $67.8 \pm 14.1$ & $55.1 \pm 8.2$ & 3.904 \\
BMI & $21.5 \pm 4.0$ & $20.3 \pm 2.6$ & t-value \\
\hline & & & 3.229 \\
& Downtown area & Rural area & 3.366 \\
Height $(\mathrm{cm})$ & $172.3 \pm 8.5$ & $169.7 \pm 7.9$ & 1.947 \\
Weight $(\mathrm{kg})$ & $63.4 \pm 15.6$ & $59.1 \pm 9.9$ & $20.0 \pm 4.1$ \\
BMI & $20.8 \pm 5.1$ & & \\
\hline
\end{tabular}

1) Mean $\pm \mathrm{SD}$

$* \mathrm{p}<0.05$ 
생이 여학생에 비해 월등하게 과체중과 비만군의 비율이 높은 것으로 나타났다. 이 역시 우리나라 의 고등학생들과 유사한 경향을 보이고 있다 (Kim \& Shin 2008; Chung \& Lee 2010; Yim 2010). 지역에 따라서는 농촌지역의 학생들이 도 심지역의 학생들에 비해 저체중의 비율은 높고 비만의 비율은 낮은 것으로 나타났으나 유의적인 차이를 보이지는 않았다.

\section{3. 체중조절 경험 실태}

체중조절행동을 해 본 경험이 있는가의 유무 는 Table 4에 나타난 바와 같다. 체중조절을 해 본 적이 있는 학생이 $35 \%$, 해 본 적이 없는 학생
이 $65 \%$ 로 동일 연령층의 우리나라 학생들보다는 경험자의 비율이 낮은 것으로 나타났다 $(\mathrm{Kim} \&$ Shin 2008; Yim 2010). 그러나 체중조절행동을 해 본 경험은 남학생(27.2\%)에 비해 여학생(41.3\%) 이 유의적으로 많은 것으로 나타나 많은 선행연 구들과 유사한 경향을 보였다(Kim \& Shin 2008; Chung \& Lee 2010; Yim 2010). 지역에 따라서도 유의적인 차이가 있어 농촌지역의 학생보다 도심 지역의 학생이 체중조절행동을 해 본 경험이 있 는 학생이 더 많은 것으로 나타났다. 그러나 우 리나라의 일부도시와 농촌지역 고등학생을 대상 으로 한 연구(Kim \& Shin 2008)에서는 도시와 농촌 간에 차이가 없는 것으로 나타나 차이를 보였다.

Table 3. Distribution of BMl of subjects

\begin{tabular}{lcccrcc}
\hline & Underweight & Normal weight & Overweight & Obesity & Total & $\chi^{2}$ \\
\hline Male & $39(19.4)^{1)}$ & $124(61.7)$ & $24(11.9)$ & $14(7.0)$ & $201(100.0)$ & $7.455^{* *}$ \\
Female & $47(20.5)$ & $166(72.5)$ & $13(5.7)$ & $3(1.3)$ & $229(100.0)$ & \\
\hline Total & $86(20.0)$ & $290(67.4)$ & $37(8.6)$ & $17(4.0)$ & $430(100.0)$ & \\
\hline Downtown area & $36(18.7)$ & $124(64.2)$ & $22(11.4)$ & $11(5.7)$ & $193(100.0)$ & 1.446 \\
Rural area & $50(21.1)$ & $166(70.0)$ & $15(6.3)$ & $6(2.5)$ & $237(100.0)$ & \\
\hline Total & $86(20.0)$ & $290(67.4)$ & $37(8.6)$ & $17(4.0)$ & $430(100.0)$ & \\
\hline
\end{tabular}

1) $\mathrm{N}(\%)$

$* * \mathrm{p}<0.01$

Table 4. The experience of weight control attempt

\begin{tabular}{|c|c|c|c|c|c|}
\hline & & Experience & Non-experience & Total & $\chi^{2}$ \\
\hline \multirow{3}{*}{ Gender } & Male & $56(27.2)^{1)}$ & $150(72.8)$ & $206(100.0)$ & \multirow{2}{*}{$10.264 * * *$} \\
\hline & Female & $102(41.6)$ & $143(58.4)$ & $245(100.0)$ & \\
\hline & Total & $158(35.0)$ & $293(65.0)$ & $451(100.0)$ & \\
\hline \multirow{3}{*}{ Region } & Downtown area & $91(44.0)$ & $116(56.0)$ & $207(100.0)$ & \multirow{2}{*}{$13.400 * * *$} \\
\hline & Rural area & $67(27.5)$ & $177(72.5)$ & $244(100.0)$ & \\
\hline & Total & $158(35.0)$ & $293(65.0)$ & $451(100.0)$ & \\
\hline \multirow{5}{*}{ BMI } & Underweight & $14(16.7)$ & $70(83.3)$ & $84(100.0)$ & \multirow{4}{*}{$8.165^{* *}$} \\
\hline & Normal weight & $100(35.1)$ & $185(64.9)$ & $285(100.0)$ & \\
\hline & Overweight & $22(59.5)$ & $15(40.5)$ & $37(100.0)$ & \\
\hline & Obesity & $8(47.1)$ & $9(52.9)$ & $17(100.0)$ & \\
\hline & Total & $144(34.0)$ & $283(66.9)$ & $423(100.0)$ & \\
\hline
\end{tabular}

1) $\mathrm{N}(\%)$

$* * \mathrm{p}<0.01$

$* * * \mathrm{p}<0.001$ 
$\mathrm{BMI}$ 로 분류한 체형군에 따라서도 유의적인 차이가 있었는데 저체중군이나 정상체중군보다 과체중군이나 비만군에서 체중조절을 해본 사람 의 비율이 더 높은 것으로 나타났다. 이는 많은 선행연구들에서도 동일한 결과를 보이고 있다 (Her et al. 2003; Soh et al. 2008; Choi \& Ro 2010; Chung \& Lee 2010; Kang 2012).

\section{4. 체형에 대한 인식}

청소년들의 체중조절행동에 영향을 미치는 요 인들은 다양하나 그 중 체형에 대한 인식도 큰 영향을 미친다고 한다(Choi \& Ro 2010; Ryu \& Contento 2011). 이에 조사대상자들이 본인의 체 형에 대해 정확하게 인식하고 있는지, 어떤 체형 을 선호하는지 등 인식을 조사한 결과는 Table 5 에 나타난 바와 같다. 현재의 체형에 대한 점수 가 남학생은 4.79, 여학생은 4.19로 나타났는데 표준체형의 값이 5.00 인 것과 조사대상자들의 $\mathrm{BMI}$ 평균값 등을 고려할 때 현재의 체형에 대한
인식은 비교적 적절한 것으로 생각된다. 그리고 현재의 체형에 대한 인식은 남 - 녀 간에 차이가 없는 것으로 나타났다.

그러나 본인이 원하는 체형과 이상적이라고 생각하는 체형에 대한 인식은 남녀 간에 유의적 인 차이가 있었다. 즉 남학생은 본인이 희망하는 체형의 평균값은 4.74 이고 이상적이라고 생각하 는 체형의 평균값도 4.77 로 현재의 체형과 차이 가 없어 본인의 현 체형에 대해 만족하고 있는 것으로 생각되었다. 그에 반해 여학생은 매우 마 른체형(3.00)을 원하고 있었고, 또한 마른 체형 (3.04)을 이상적인 것으로 생각하고 있었다. 이는 현재 본인의 체형(4.19)과 많은 차이가 있어 여학 생(1.08)들이 남학생(0.11)에 비해 체형에 대한 불 만족도가 유의적으로 높음을 알 수 있었다. 이는 선행연구들(Albright 1999; Ryu \& Yoon 1999; Williams \& Currie 2000; Kim \& Shin 2008; Yim 2010)과 유사한 경향이었다. 그러나 거주하는 지 역에 따라서는 체형의 인식은 차이가 없는 것으

Table 5. Perception of body image of the subjects

\begin{tabular}{|c|c|c|c|c|c|}
\hline & \multicolumn{4}{|c|}{ Gender } & \multirow{2}{*}{ t-value } \\
\hline & \multicolumn{2}{|c|}{ Male } & \multicolumn{2}{|c|}{ Female } & \\
\hline Current figure & \multicolumn{2}{|c|}{$4.79 \pm 1.58^{2)}$} & \multicolumn{2}{|c|}{$4.19 \pm 1.50$} & 4.075 \\
\hline Desired figure & \multicolumn{2}{|c|}{$4.74 \pm 0.87$} & \multicolumn{2}{|c|}{$3.00 \pm 1.05$} & $18.367 *$ \\
\hline Ideal figure & \multicolumn{2}{|c|}{$4.77 \pm 0.82$} & \multicolumn{2}{|c|}{$3.04 \pm 0.99$} & $19.299 *$ \\
\hline \multirow[t]{3}{*}{ D.B.I ${ }^{1)}$} & \multicolumn{2}{|c|}{$0.11 \pm 1.54$} & \multicolumn{2}{|c|}{$1.08 \pm 1.32$} & $-7.148 * * *$ \\
\hline & \multicolumn{4}{|c|}{ Region } & \multirow{2}{*}{ t-value } \\
\hline & \multicolumn{2}{|c|}{ Downtown area } & \multicolumn{2}{|c|}{ Rural area } & \\
\hline Current figure & \multicolumn{2}{|c|}{$4.49 \pm 1.66$} & \multicolumn{2}{|c|}{$4.45 \pm 1.49$} & 0.261 \\
\hline Desired figure & \multicolumn{2}{|c|}{$3.78 \pm 1.31$} & \multicolumn{2}{|c|}{$3.81 \pm 1.30$} & -0.206 \\
\hline Ideal figure & \multicolumn{2}{|c|}{$3.84 \pm 1.26$} & \multicolumn{2}{|c|}{$3.83 \pm 1.25$} & 0.071 \\
\hline \multirow[t]{3}{*}{ D.B.I } & \multicolumn{2}{|c|}{$0.71 \pm 1.52$} & \multicolumn{2}{|c|}{$0.61 \pm 1.51$} & 0.738 \\
\hline & \multicolumn{4}{|c|}{ BMI } & \multirow{2}{*}{ F-value } \\
\hline & Under weight & Normal weight & Overweight & Obesity & \\
\hline Current figure & $3.23 \pm 1.18$ & $4.38 \pm 1.21$ & $6.42 \pm 1.03$ & $6.82 \pm 2.16$ & $77.492 * * *$ \\
\hline Desired figure & $3.73 \pm 1.40$ & $3.66 \pm 1.23$ & $4.61 \pm 0.93$ & $5.06 \pm 1.39$ & $12.029 * * *$ \\
\hline Ideal figure & $3.80 \pm 1.31$ & $3.70 \pm 1.26$ & $4.56 \pm 0.91$ & $4.71 \pm 1.16$ & $7.932 * * *$ \\
\hline D.B.I & $-0.43 \pm 1.29$ & $0.70 \pm 1.36$ & $1.76 \pm 1.07$ & $1.76 \pm 1.52$ & $31.272 * * *$ \\
\hline
\end{tabular}

1) D.B.I: dissatisfaction of body image

2) Mean $\pm \mathrm{SD}$

${ }^{*} \mathrm{p}<0.05, * * * \mathrm{p}<0.001$ 
로 나타났다. 한국의 일부 도시와 농촌지역의 고 등학생들을 대상으로 한 연구(Kim \& Shin 2008) 에서는 남학생은 도시와 농촌의 차이가 없었으나 여학생은 농촌보다 도시에서 매우 마른 체형에 대한 선호도가 유의적으로 높아 차이가 있는 것 으로 보고되었다.

$\mathrm{BMI}$ 로 분류한 체형군에 따라서도 체형에 대 한 인식은 유의적으로 차이가 나는 것으로 나타 났다. 저체중군은 현재 체형(3.48)보다 조금 더 살찐 체형(3.69)을 원하고 있었고, 이상적(3.80)으 로 생각하고 있었다. 정상군(4.32)과 과체중군 (6.03) 및 비만군(6.65)은 각각 현재 체형보다 더 마른 체형인 $3.62,4.59,4.74$ 를 원하고 있었고, 이 에 따라 현재의 체형이 뚱뚱할수록 체형에 대한 불만족도가 유의적으로 높은 것으로 나타났다. 이는 많은 선행연구들(Ryu 1997; Ryu \& Yoon 1998; Her et al. 2003; Soh et al. 2008; Choi \& Ro 2010)과 유사한 결과이다.

그러나 체형에 대한 인식이 평균적으로는 왜 곡되지 않은 것으로 나타났다 하더라도 개인적으 로 자신의 체형에 대한 과소평가와 과대평가가 상쇄되어 평균치를 나타낼 수도 있으므로 현재의 체위인 $\mathrm{BMI}$ 값과 자신의 체형에 대해 인식을 개 별적으로 비교 분석하여 체형 인식에 대한 왜곡
정도를 나타낸 결과는 Table 6과 같다. 이 결과에 의하면 전체 대상자의 $54 \%$ 는 본인의 현재 체형 에 대해 적절하게 인식하고 있었으나 $46 \%$ 는 현 재의 체형에 대해 왜곡하고 있는 것으로 나타났 다. 왜곡된 체형인식을 가진 대상자 중 $25.8 \%$ 는 자기 자신을 실제보다 더 마른 것으로 인식하였 으며, $20.1 \%$ 는 자기 자신을 실제보다 더 살찐 것 으로 인식하였다. 이는 성별과 거주 지역에 따른 차이는 없는 것으로 나타났다. 그러나 현재의 체 형에 따라서는 유의적인 차이가 있었는데 저체중 과 정상체중인 학생들은 자신을 현재의 체형보다 더 살찐 것으로 인식하고 있는데 반해 과체중이 나 비만인 학생들은 현재의 체형보다 더 마른 겻 으로 인식하고 있었다. 이는 선행연구들(Ryu \& Contento 2011; Lee \& Sun 2013)에서도 동일하게 나타나는 경향이다.

\section{5. 섭식장애 실태}

EAT-26은 가장 널리 사용되는 섭식장애의 특 성을 표준화한 도구이다(Garner et al. 1982). 이는 섭식장애를 진단할 수 있는 도구는 아니지만 식 사와 관련된 행동과 태도, 감정 등 섭식장애의 위험을 파악하는데 사용될 수 있다. EAT-26을 이 용하여 섭식장애의 위험 정도를 조사한 결과는

Table 6. Distortion of body image perception of the subjects

\begin{tabular}{|c|c|c|c|c|c|c|}
\hline & & \multirow{2}{*}{ Non-distortion } & \multicolumn{2}{|c|}{ Distortion } & \multirow{2}{*}{ Total } & \multirow{2}{*}{$\chi^{2}$} \\
\hline & & & Underestimated & Overestimated & & \\
\hline \multirow{2}{*}{ Gender } & Male & $114(54.8)^{1)}$ & $48(23.1)$ & $46(22.1)$ & $208(100.0)$ & \multirow{2}{*}{1.900} \\
\hline & Female & $133(53.4)$ & $70(28.1)$ & $46(18.5)$ & $249(100.0)$ & \\
\hline Total & & $247(54.0)$ & $118(25.8)$ & $92(20.1)$ & $457(100.0)$ & \\
\hline \multirow{2}{*}{ Region } & Downtown area & $116(55.8)$ & $55(26.4)$ & $37(17.8)$ & $208(100.0)$ & \multirow{2}{*}{1.307} \\
\hline & Rural area & $131(52.6)$ & $63(25.3)$ & $55(22.1)$ & $249(100.0)$ & \\
\hline Total & & $247(54.0)$ & $118(25.8)$ & $92(20.1)$ & $457(100.0)$ & \\
\hline \multirow{4}{*}{ BMI } & Underweight & $54(62.8)$ & $6(7.0)$ & $26(30.2)$ & $86(100.0)$ & \multirow{4}{*}{$20.309 * * *$} \\
\hline & Normal weight & $165(56.9)$ & $82(28.3)$ & $43(14.8)$ & $290(100.0)$ & \\
\hline & Overweight & $16(43.2)$ & $20(54.1)$ & $1(2.7)$ & $37(100.0)$ & \\
\hline & Obesity & $10(58.8)$ & $7(41.2)$ & $0(0.0)$ & $17(100.0)$ & \\
\hline Total & & $245(57.0)$ & $115(26.7)$ & $70(16.3)$ & $430(100.0)$ & \\
\hline
\end{tabular}

1) $\mathrm{N}(\%)$ 
Table 7. Distribution of eating disorder of the subjects

\begin{tabular}{llccccc}
\hline & & Normal & Risk & Eating disorder & Total & $\chi^{2}$ \\
\hline \multirow{2}{*}{ Gender } & Male & $162(77.9)^{1)}$ & $35(16.8)$ & $11(5.3)$ & $208(100.0)$ & 3.659 \\
& Female & $175(70.3)$ & $53(21.3)$ & $21(8.4)$ & $249(100.0)$ & \\
\hline \multirow{2}{*}{ Total } & & $337(73.7)$ & $88(19.3)$ & $32(7.0)$ & $457(100.0)$ & \\
\hline \multirow{2}{*}{ Region } & Downtown area & $142(68.3)$ & $49(23.6)$ & $17(8.2)$ & $208(100.0)$ & $5.966^{*}$ \\
& Rural area & $195(78.3)$ & $39(15.7)$ & $15(6.0)$ & $249(100.0)$ & \\
\hline Total & & $337(73.7)$ & $88(19.3)$ & $32(7.0)$ & $457(100.0)$ & \\
\hline \multirow{2}{*}{ BMI } & Underweight & $66(76.7)$ & $17(19.8)$ & $3(3.5)$ & $86(100.0)$ \\
& Normal weight & $217(74.8)$ & $53(18.3)$ & $20(6.9)$ & $290(100.0)$ \\
& Overweight & $25(67.6)$ & $7(18.9)$ & $5(13.5)$ & $37(100.0)$ & 1.931 \\
Total & Obesity & $10(58.8)$ & $4(23.5)$ & $3(17.6)$ & $17(100.0)$ \\
\hline
\end{tabular}

1) $\mathrm{N}(\%)$

${ }^{*} \mathrm{p}<0.05$

Table 7에 나타난 바와 같다. 섭식장애로 진행될 수 있는 위험군의 비율은 $7.0 \%$ 로 나타났다. 많은 선행연구들(Hwang \& Shin 2000; Song \& Park 2003; Choi \& Cheon 2007; Yim 2010; Ryu \& Contento 2011)에서 남성보다는 여성에게서 섭식 장애의 증상이 많이 나타나는 것으로 보고된 것 과는 달리 본 연구대상자들에 있어서는 남학생보 다 여학생에서 섭식장애의 위험군이 많은 비율을 보이긴 하였으나 통계적인 유의성은 나타나지 않 았다. 지역에 따라서는 유의적인 차이를 보였는 데 도심에 있는 학생들이 농촌지역에 사는 학생 들에 비해 섭식장애의 위험군(23.6\%)과 섭식장애 군(8.2\%)이 유의적으로 많은 것으로 나타났다. $\mathrm{BMI}$ 로 분류한 체형군에 따라서는 유의적인 차이 가 없는 것으로 나타났다.

\section{IV. 요약 및 결론}

본 연구는 중국 산동성 연태시 고등학생 452 명을 대상으로 이들의 체위의 실태를 알아보고, 체중조절행동의 경험, 체형에 대한 인식, 섭식장 애의 정도를 조사하였다. 그리고 성별과 지역에 따른 차이를 비교하였다. 조사결과는 다음과 같다.

1. 조사대상자 중 남학생은 평균 $177.6 \mathrm{~cm}$ 에 67.8 $\mathrm{kg}$ 으로 $\mathrm{BMI}$ 는 21.46이었다. 여학생은 평균 165.1 $\mathrm{cm}, 55.1 \mathrm{~kg}$ 으로 $\mathrm{BMI}$ 는 20.26 이었다.

2. 체질량지수(BMI)를 기준으로 체형군을 분류 한 결과는 저체중군이 $20.0 \%$, 과체중군과 비만군 이 각각 $8.6 \%$ 와 $4.0 \%$ 로 나타났다. 남학생의 과체 중과 비만 비율이 여학생보다 유의적으로 높은 것으로 나타났으나 지역에 따른 차이는 없는 것 으로 나타났다.

3. 체중조절의 경험이 있는 학생이 $35 \%$ 였는데 이는 남학생(27.2\%)에 비해 여학생(41.6\%)이 유 의적으로 많았으며 농촌지역 학생 $27.5 \%)$ 에 비해 도심지역 학생 $(44.0 \%)$ 이 유의적으로 많았다. 체 형군에 있어서는 정상과 저체중군에 비해 과체중 이상의 체형군에서 경험이 유의적으로 많은 것으 로 나타났다.

4. 체형에 대한 인식에서 현재의 체형에 대한 인식은 평균적으로는 왜곡이 없는 것으로 보였으 나 저체중과 정상체중인 학생들은 현재의 체형보 다 본인이 더 살찐 것으로 인식하고 있는데 반해 과체중이나 비만인 학생들은 현재의 체형보다 더 마른 것으로 인식하고 있어서 차이를 보였다. 현 재의 체형에 대한 인식은 성별과 지역에 따른 차 이는 없으나 원하는 체형과 이상적이라고 생각하 는 체형은 여학생이 남학생보다 더 마른 체형을 원하고 이상적이라고 생각하기 때문에 체형에 대 한 불만족도가 유의적으로 높은 것으로 나타났 
다. 또한 체형군에 따른 체형인식은 유의적인 차 이가 있어 비만할수록 체형에 대한 불만족도가 높은 것으로 나타났다.

5. 섭식장애군은 전체의 $7.0 \%$ 로 나타났고, 섭 식장애 위험군은 $19.3 \%$ 로 나타났다. 이는 성별에 따른 차이는 없었으나 농촌지역의 학생보다 도심 지역의 학생에서 유의적으로 많은 것으로 나타났다. 이상의 결과를 통해 중국 산동성 연태시의 고 등학생들은 비만의 문제 뿐 아니라 저체중의 문 제도 우려할 만한 것으로 나타났고 특히 여학생 의 경우 과체중과 비만의 비율에 비해 저체중의 비율이 월등히 많은 것으로 나타났다. 그럼에도 불구하고 여학생의 체중조절 경험이 매우 높은 것과 원하는 체형과 이상적이라고 생각하는 체형 이 매우 마른 체형이기 때문에 체형에 대한 불만 족도가 높은 것은 매우 심각한 문제로 생각된다. 그리고 섭식장애군과 섭식장애 위험군의 비율이 매우 높은 것으로 나타나 바람직한 체형과 체중 조절의 방법에 대한 교육이 필요할 것으로 생각 된다. 특히 도심지역에 거주하는 여학생이 가장 중요한 영양교육의 대상인 것으로 생각된다.

\section{References}

Albright AV(1999) Vulnerability to depression. Nurs Clin North Am 34(2), 393-407

Bellizzi MC, Dietz WH(1999) Workshop on childhood obesity: summary of the discussion. Am J Clin Uutr 70, 173-175

Cash TF, Santos MT, Williams EF(2005) Coping with body-image threats and challenges validation of the Body Image Coping Strategies Inventory. J Psychos Res 58(2), 191-199

Chen H, Jackson T(2008) Prevalence and sociodemographic correlates of eating disorder endorsements among adolescents and young adults from China. Eur Eat Disord Rev 16(5), 375-385

Chengye J(2004) Body mass index reference norm for screening overweight and obesity in Chines children and adolescents. Chin J Epidemiol 25, 97-102

Choi MS, Cheon SH(2007) Internalization of the socio-cultural attitudes, body shape satisfaction, anger and eating attitudes in college women. Korean J Women Health Nurs 13(4), 327-335

Choi IS, Ro $\operatorname{HK}(2010)$ A comparison study on middle school students of Gwangju and Jeonnam in terms of dietary behavior, body perception and weight control concerns according to BMI. Korean Soc Food Sci Nutr 39(3), 383-391

Chung HK, Lee HY(2010) The concepts of weight control and dietary behavior in high school seniors. Korean J Nutr 43(6), 607-619

Currin L, Schmidt U, Treasure J, Jick H(2005) Time trends in eating disorder incidence. $\mathrm{Br} \mathrm{J}$ Psychiatry 186(2), 132-135

Garner DM, Olmsted MP, Bohr Y, Garfinkel P(1982) The eating attitudes test: psychometric features and clinical correlates. Psychol Med 12, 871-878

Ge KY, Zhai FY, Yan HC(1995) The dietary and nutritional status of Chinese in the nineties. Acta Nutrimenta Sinica 17(2), 123-133

Her ES, Kang HJ, Lee $\mathrm{KH}(2003)$ The factor associated with weight control experiences among adolescents-based on self-esteem, body-cathexis, attitudes toward the body, anthropometric characteristics and perception of body shape. Korean $\mathrm{J}$ Community Nutr 8(5), 656-666

Ho TF, Tai BC, Lee EL, Cheng S, Liow PH(2006) Prevalence and profile of females at risk of eating disorders in Singapore. Singapore Med J 47(6), 499-503

Huon GF, Mingyi Q, Oliver K, Xiao G(2002) A large-scale survey of eating disorder symptomatology among female adolescents in the People's Republic of China. Int J Eat Disord 32(2), 192-205

Hwang RH, Shin HS(2000) A study on eating disorder, body image and self-esteem of high school girls. Korean J Women Health Nurs 6(1), 129-141

Ingledew DK, Sullivan G(2002) Effects of body mass and body image on exercise motives in adolescence. Psychol Sport Exercise 3(4), 323-338

Kang KS(2012) The body mass index(BMI), body image recognition, weight control behavior of nursing students. J Korea Academia-Industrial Cooperation Soc 13(8), 3492-3499

Kim YK, Shin WS(2008) A comparison study on perception of body image and dietary habits of high school students between urban and rural areas. Korean J Community Nutr 13(2), 153-163

Kwon WJ, Chang KJ, Kim SK(2002) Comparison of nutrient intake, dietary behavior, perception of body image and iron nutritional status among female high school students of urban and rural areas in Kyunggi-do. Korean J Nutr 35(1), 90-101

Lee JS, Yun JW(2003) A study on perception about body image, diatary attitude, dietary self-efficacy and nutrient intakes of high school students in Busan. J Korean Soc Food Sci Nutr 32, 295-301

Lee YM, Sun L(2013) The study of perception in 
body somatotype and dietary behaviors -The comparative study between Korean and Chinese college students-. Korean J Community Nutr 18(1), $25-44$

Liang J, Zhang F, Pan W, Feng L(2008) Study on cognition situation of obesity and weight reduction behavior in undergraduate students. Modern Prev Med 35(15), 2-867

Lobstein T, Baur L, Uaut R(2004) Obesity in children and young people: A crisis in public health. Obes Rev 5(S1), 4-104

Ministry of Health, PRC, Ministry of Science and Technology of People's Republic of China, National Bureau of Statistics of China(2004) Chinese National Nutrition and Health Status. Available from http://news.xinhuanet.com [cited 2004 October 12]

Must A, Spadano J, Coakley EH, Field AE, Colditz G, Dietz WH(1999) The disease burden associated with overweight and obesity. J Am Med Assoc 282(16), 1523-1529

Psujek JK, Martz DM, Curtin L(2004) Gender differences in the association among nicotine dependence, body image depression, and anxiety with in a college population. Addictive Behav 29(2), 375-380

Ryu HK(1997) A study of adolescents' concern and perception about body image -at Miryang City-. Korean J Community Nutr 2(2), 197-205

Ryu HK, Contento IR(2011) A study on body image perception and eating disorders by birth-place and the length of residence in USA in Korean American college students. Korean J Community Nutr 16(1), 113-125

Ryu HK, Yoon JS(1998) Relations of perception of obesity and experiences of weight control and body image in high school students. Korean $\mathrm{J}$ Community Nutr 3(2), 202-209
Soh HK, Lee EJ, Choi BS(2008) The development of nutrition education program for improvement of body perception of middle school girls(II). Korean J Food Culture 23, 130-137

Song KY, Park CS(2003) Eating habits, trend of disordered eating, weight reduction practice and body size evaluation of college students in Seoul. Korean J Women Health Nurs 9(40), 457-466

Stunkard AJ, Sorensen T, Schulsinger F(1980) Use of the Danish adoption resister for the study of obesity and thinness. In: Kety S, Genetics of Neurological and Psychiatric Disorders. Raven Press: New York, pp115-120

Treasure J, Cludino AM, Zucker N(2010) Eating disorders. Lancet 375(9714), 583-593

Williams J, Currie C(2000) Self-esteem and physical development in early adolescence: Pubertal timing and body image, J Early Adolescence 20, 129149

Yamatsuji M, Yamashita T, Arii I, Taga C, Tatara N, Fukui $\mathrm{K}(2003)$ Seasonal variations in eating disorder subtypes in Japan, Int $\mathrm{J}$ Eat Disord 33(1), 71-77

Yang XG, Zhai FY, Pu JH(2010) Chinese national nutrition survey. China Prev Med 1(11), 5-7

Yim KS(2010) Effects of obesity, body image dissatisfaction and dietary habits on the risk of disturbed eating attitudes among high school students in Gyunggi province, Korea. Korean J Community Nutr 15(5), 656-669

Zhou BF(2002) Predictive values of body mass index and waist circumference for risk factors of certain related disease in Chinese adults-study on optimal cut-off points of body mass index and waist circumference in Chinese adults. Biomed Environment Sci 15, 83-95 